\title{
Keynote: Bridging the Gap Between Requirements and Design
}

\author{
Craig Errey \\ The Performance Technologies Group Pty Ltd \\ Sydney, Australia \\ craige@ptg-global.com
}

\section{Brief Bio}

Craig is the Managing Director of The Performance Technologies Group (PTG). PTG specialises in requirements modelling, high performance user interface design, usability and accessibility. PTG improves customer experience and business performance with all technologies - websites, intranets, business applications, speech recognition systems, interactive voice response, interactive television and hardware.

PTG placed 64th in the 2004 BRW Fast 100, with an average of $50 \%$ growth per annum, since starting in 1999. PTG currently employs over 20 people with backgrounds ranging from psychology, computer science, information environment, marketing, business strategy and human computer interaction.

Craig's primary role is the research, development and implementation of the company's IP and methodologies. His credentials and experience encompass the disciplines of psychology, HR consulting, change management, and technology. By aligning business, marketing and customer strategies to website and application design, he helps organisations create real and measurable value for people and business. As a psychologist, he understands the way people think and is therefore able to create systems that are simple, user-friendly and effective.

Craig has consulted in usability and user interface design for Commonwealth Bank, Qantas, Vodafone, NSW Department of Commerce, ANZ, Defence, Department of Health and Ageing, IBM, Motorola, National Bank, QBE MM, Hutchison Telecoms / Orange / 3, NSW RTA, Tourism Australia, Tourism NSW, Zurich, Telstra, E*trade and Citibank.

Craig holds a Master's Degree in Organisational Psychology from UNSW, is a member of the APS and the APS College of Organisational Psychologists, and is a Registered Psychologist in NSW.

\section{Talk Abstract}

Despite billions of dollars being spent on IT around the world each year on business applications, Excel spread sheets continue to be the corporate chewing gum of choice. 
IT has failed to consistently and predictably produce the results required of business. IT has focussed on technical aspects - efficiency, response times, data base optimisation, network performance, architectures, interoperability and so on.

The majority of IT projects have experienced one more of the following:

- The technology solution is chosen before the requirements are know,

- The requirements change throughout the project,

- They're late,

- They don't deliver what was expected,

- They cost more that expected,

- They don't work the way people work.

What is needed is a bridge between business, requirements and IT. IT lacks this 'blueprint' to build an application the right way, the first time.

But it's not just IT's problem. Craig's own fields of user interface design and usability also have significant problems in their methods. There are various standards, like ISO 9241 (part 11) and ISO 13407:1999) that ultimately describe what usability is and how to measure it, but there is no systematic process to move from requirements to design. There is not even an agreed operational definition of usability, other than that used to measure it (efficiency, effectiveness and satisfaction). This means that if two designers approach the same user interface design process, independently, they will come up with markedly different designs. This is not what is expected from a 'quality' process.

Craig will be presenting a basis for a new framework for business IT that integrates business and user requirements using a blend software engineering, psychology and design principles to create a precise blueprint that IT can build from that bridges requirements to design - that is, getting IT right the first time. 